\title{
Immunotherapies and COVID-19 mortality: a multidisciplinary open data analysis based on FDA's Adverse Event Reporting System
}

During the COVID-19 pandemic, the risks and potential benefits of immunotherapies for the treatment of autoimmune disorders are still not well defined, and many cohort studies neither took the epidemiological dynamics of COVID-19 nor the potential capacities of the local healthcare systems in their outcome analysis into account. Due to a pronounced heterogeneity in the outcome reports of different participating countries, the large 'COVID-19 Global Rheumatology Alliance registry' addressed this issue using a 'cluster design' and shed light on factors associated with a more severe COVID-19 course in their study population. ${ }^{1}$ We here present data of the US Food and Drug Administration (FDA) Adverse Event Reporting System (FAERS), ${ }^{2}$ a postmarketing, selfreporting, open-access pharmacovigilance platform that contains international data of COVID-19 cases. Sources of FAERS are voluntary reports from healthcare professionals and consumers. We combine this data set with local measurements of the course of the pandemic (from Oxford University's 'Our World in Data'3 and the potential resiliency of the respective healthcare systems (from 'World Bank'; see online supplemental table 1 for full source information). Only patients with the diagnosis of an autoimmune disorder and a single immunotherapy (required group size: $\mathrm{n} \geq 100$ ) at the time point of COVID-19 were analysed by multivariable regression analysis (online supplemental figure 1), limiting the generalisability of our data, for example, concerning combination therapy scenarios (online supplemental figure 1).

The mean age of patients in our cohort $(n=2103)$ was 51.3 years (range 3-92 years; SD 14.9), female sex was more prevalent $(1372 / 2103,65.2 \%)$ and the majority of cases was reported in the USA/Canada $(1285 / 2103,61.1 \%)$. Inflammatory joint disease (846/2103, 40.2\%), multiple sclerosis (474/2103, $22.5 \%)$ and inflammatory skin disease $(435 / 2103,20.7 \%)$ were the most prevalent diagnoses. Anti-tumour necrosis factor $\alpha$ $(\mathrm{TNF} \alpha)$ therapies were the most frequently used medications for the underlying autoimmune disease $(714 / 2103,34 \%)$, followed by anti-CD20 therapies (388/2103, 18.4\%). Additional cohort characteristics are shown in online supplemental table 2 and the monthly distribution of cases and cases by country in online supplemental figure 2 . 


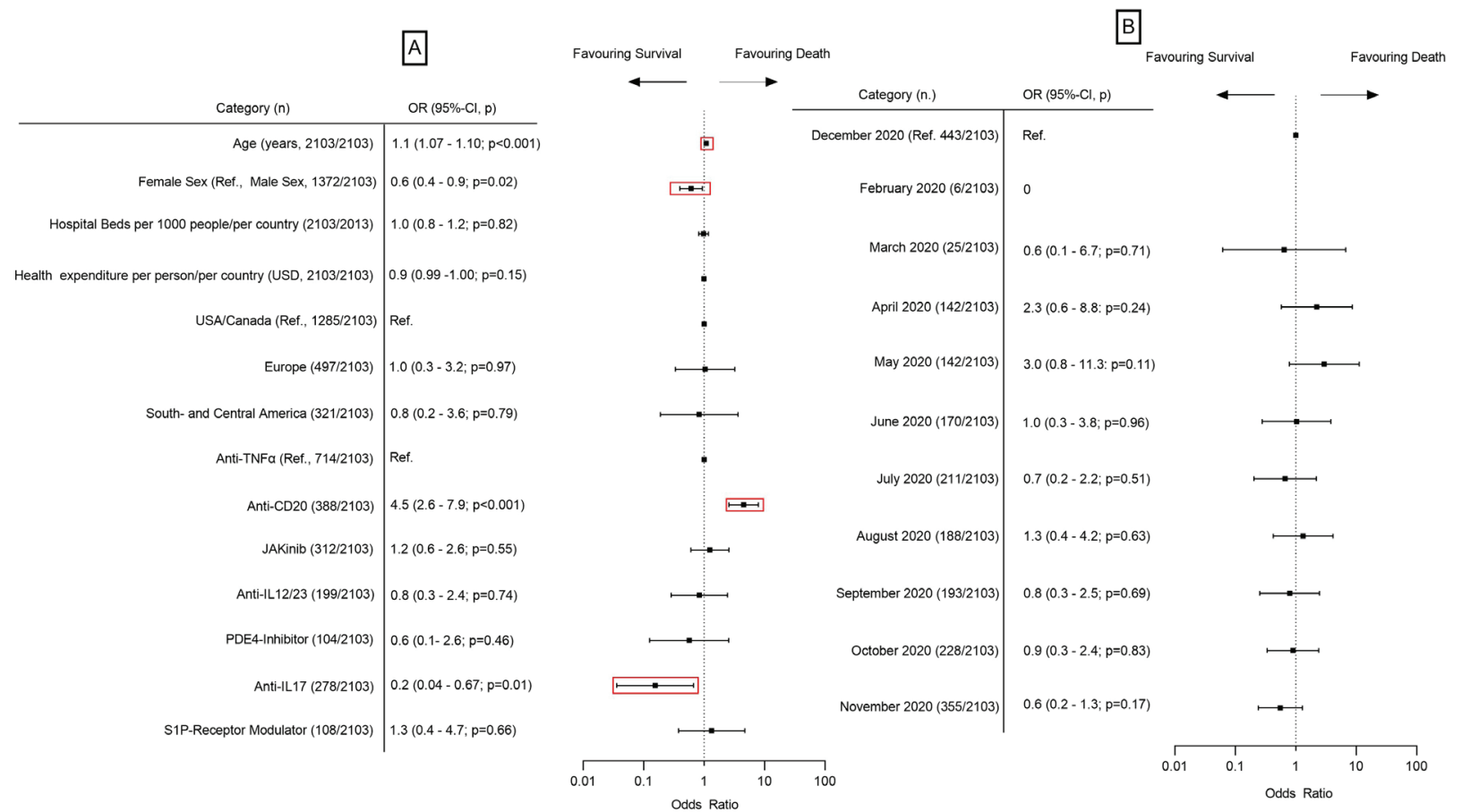

Figure 1 MLR showing the OR for 'death': 95\% Cls and $p$ values of the independent variables on a 10-log scale. (A) ORs for age, sex, hospital beds per 1000 persons/per country, health expenditure per person/per country (in US\$), region and immunotherapy. (B) ORs for each month of 'initial FDA received date'. To control for the potential 'expectation bias' of FAERS, we included the variable 'ratio of total reports to FAERS to the number of reported deaths to FAERS for each drug in 2018-2020 excluding COVID-19 cases' (2.8; 0.1 to 84.2; $p=0.56$; not displayed). As reference groups (Region, Immunotherapy, Month), we chose the one with the highest number. Nagelkerke's $\mathrm{R}^{2}$ is 0.24 . For February 2020 , no deaths have been reported to FAERS; therefore, the OR for February is 0. MLR was conducted with SPSS V.25 (IBM, USA, 2017). For more information regarding multivariable analysis adjusted for "month of event" instead of "initial FDA received date" see online supplemental figure 3 and for univariable analysis online supplemental figure 4 . Not displayed: 'case fatality rate per month of initial FDA received date/country' (OR $0.5 ; 0.0$ to 2479.3; $p=0.86)$, 'new cases per population per month and country' (OR 51.5; 0.00 to 3.124E+37; $p=0.93$ ) and 'new deaths per population per month and country' (OR 0; $p=0.54$ ). CD-20, Cluster of Differentiation-20; FAERS, US Food and Drug Administration (FDA) Adverse Event Reporting System; IL-12/23, interleukin 12/23; IL-17, interleukin 17; JAKinib, Janus kinase inhibitor; MLR, multivariable logistic regression; PDE4-Inhibitor, phosphodiesterase-4 inhibitor; S1P-Receptor Modulator, sphingosine-1 phosphate receptor modulator; TNF $\alpha$, tumour necrosis factor $\alpha$.

In all, $26.3 \%$ of the reported patients were hospitalised $(553 / 2103)$, and the overall reported mortality rate in our cohort was $5.1 \%(107 / 2103$; for other outcomes, see online supplemental table 3$)$. In the multivariable logistic regression analysis, age (OR per year $1.1 ; 95 \%$ CI 1.07 to $1.1 ; \mathrm{p}<0.001)$ and female sex (OR $0.6 ; 95 \%$ CI 0.4 to $0.9 ; \mathrm{p}=0.02$ ) were significant predictors of mortality. Regarding immunotherapies, patients under anti-CD20 therapies had an increased mortality (OR 4.5; $95 \%$ CI 2.6 to $7.9 ; \mathrm{p}<0.001)$, whereas those under anti-IL17 therapies had a reduced mortality (OR $0.2 ; 95 \%$ CI 0.04 to 0.67 ; $\mathrm{p}=0.01$ ) compared with anti-TNF $\alpha$ therapies (reference group; figure 1).

In summary, using international open data sets and adjusting for local infectious diseases dynamics and the potential resilience of the national healthcare systems, our study demonstrates that anti-CD20 therapies are associated with a higher COVID-19 mortality risk in people with autoimmune disorders. This finding is in line with other cohort studies. ${ }^{14}$ Regarding the potential protective capacities of anti-IL17 treatments, further studies are needed. This study also identified age and male sex as relevant predictors of COVID-19-associated mortality, which should therefore be taken into account in individual risk-benefit assessments. Our study has several limitations, for example, the fact that FAERS reports basic information on patients. We could not analyse disease-specific characteristics, comorbidities and risk factors, which have previously shown to influence mortality risks, thus representing a limitation of our analysis. Furthermore, adjustment for individual disease groups was not possible due to multicollinearity to immunotherapies. Biological therapies and recently approved oral immunotherapies are over-represented compared with classical immunotherapies, pointing towards a selection bias of FAERS. Furthermore, we cannot report the method of SARS-CoV-2 detection, as this information is not included in the FAERS data set.

Finally, we consider the use of combined open-access, pharmacoepidemiological data and a multidisciplinary approach, despite its limitations, as a valuable tool to address the various issues posed by the SARS-CoV-2 pandemic. Our findings might represent a complement to already published data and call for intensified investigations within larger cohort and translational studies. Maximilian Pistor $\odot,{ }^{1}$ Andreas G F Hoepner, ${ }^{2,3}$ Yanan Lin, ${ }^{2}$ Simon Jung,
Claudio L Bassetti, ${ }^{1}$ Andrew Chan, ${ }^{1}$ Anke Salmen, ${ }^{1}$ Robert Hoepner ${ }^{1}$

${ }^{1}$ Department of Neurology, Inselspital, Bern University Hospital, University of Bern, Bern, Switzerland

${ }^{2}$ Michael Smurfit Graduate Business School—Department of Banking \& Finance, University College Dublin, Dublin, Ireland

${ }^{3}$ Platform for Sustainable Finance-Department for Financial Stability and Capital Markets (DG FISMA), European Commission, Brussels, Belgium

Correspondence to Dr Robert Hoepner, Department of Neurology, Inselspital University Hospital Bern, Bern 3012, Switzerland; robert.hoepner@insel.ch 
Handling editor Josef S Smolen

Contributors $\mathrm{RH}, \mathrm{MP}, \mathrm{AGFH}, \mathrm{YL}$ and $\mathrm{AS}$ were involved in study design. MP, RH, $A G F H$ and $Y L$ were involved in data analysis. RH, MP, AGFH, YL, AS, SJ, AC and CB were involved in data Interpretation, data review and manuscript preparation.

Funding MP was funded by a translational research grant from the Department of Neurology, University Hospital Bern, Switzerland, to guarantee protected research time.

Map disclaimer The inclusion of any map (including the depiction of any boundaries therein), or of any geographic or locational reference, does not imply the expression of any opinion whatsoever on the part of BMJ concerning the legal status of any country, territory, jurisdiction or area or of its authorities. Any such expression remains solely that of the relevant source and is not endorsed by BMJ. Maps are provided without any warranty of any kind, either express or implied.

Competing interests AGFH (Department of Banking \& Finance, Michael Smurfit Graduate Business School, University College Dublin, Dublin, Republic of Ireland and Platform for Sustainable Finance, Department for Financial Stability and Capital Markets (DG FISMA), European Commission, European Union (EU)) and YL (Department of Banking \& Finance, Michael Smurfit Graduate Business School, University College Dublin, Dublin, Republic of Ireland) acknowledge funding from the European Union's Horizon 2020 research and innovation program for research on Fintech (Grant No. H2020-ICT-825215) and Science Foundation Ireland (Award 19/ FIP/AI/7539). The views expressed in this paper are not necessarily shared by other members of the Platform for Sustainable Finance or DG FISMA. AC (Department of Neurology, Inselspital, Bern University Hospital, University of Bern, Bern, Switzerland) has served on advisory boards for, and received funding for travel or speaker honoraria from, Actelion-Janssen, Almirall, Bayer, Biogen, Celgene, Sanofi-Genzyme, Merck, Novartis, Roche and Teva, all for hospital research funds, and received research support from Biogen, Genzyme and UCB. AC is associate editor of the European Journal of Neurology and serves on the editorial board for Clinical and Translational Neuroscience and as topic editor for the Journal of International Medical Research; all not related to that work. AS received speaker honoraria and/ or travel compensation for activities with Almirall Hermal GmbH, Biogen, Merck, Novartis, Roche, and Sanofi Genzyme and research support by the Swiss MS Society; all not related to this work. $\mathrm{RH}$ received speaker/advisor honorary from Merck, Novartis, Roche, Biogen, Alexion, Sanofi, Bristol-Myers Squibb and Almirall. He received research support within the last 5 years from Roche, Merck, Sanofi, Biogen and Bristol-Myers Squibb. He also received research grants from the Swiss MS Society; all not related to that work.

Patient consent for publication Not required.

Provenance and peer review Not commissioned; externally peer reviewed. Supplemental material This content has been supplied by the author(s). It has not been vetted by BMJ Publishing Group Limited (BMJ) and may not have been peer-reviewed. Any opinions or recommendations discussed are solely those of the author(s) and are not endorsed by BMJ. BMJ disclaims all liability and responsibility arising from any reliance placed on the content. Where the content includes any translated material, BMJ does not warrant the accuracy and reliability of the translations (including but not limited to local regulations, clinical guidelines, terminology, drug names and drug dosages), and is not responsible for any error and/or omissions arising from translation and adaptation or otherwise.$$
\text { (2) }
$$$$
\text { OPEN ACCESS }
$$

Open access This is an open access article distributed in accordance with the Creative Commons Attribution Non Commercial (CC BY-NC 4.0) license, which permits others to distribute, remix, adapt, build upon this work non-commercially, and license their derivative works on different terms, provided the original work is properly cited, appropriate credit is given, any changes made indicated, and the use is non-commercial. See: http://creativecommons.org/licenses/by-nc/4.0/.

(c) Author(s) (or their employer(s)) 2021. Re-use permitted under CC BY-NC. No commercial re-use. See rights and permissions. Published by BMJ.

- Additional supplemental material is published online only. To view, please visit the journal online (http://dx.doi.org/10.1136/annrheumdis-2021-220679).

\section{Check for updates}

To cite Pistor M, Hoepner AGF, Lin Y, et al. Ann Rheum Dis 2021;80:1633-1635.
Published Online First 20 July 2021

Ann Rheum Dis 2021;80:1633-1635. doi:10.1136/annrheumdis-2021-220679

\section{ORCID iD}

Maximilian Pistor http://orcid.org/0000-0002-0703-9974

\section{REFERENCES}

1 Strangfeld A, Schäfer M, Gianfrancesco MA, et al. Factors associated with COVID-19related death in people with rheumatic diseases: results from the COVID-19 global rheumatology alliance physician-reported registry. Ann Rheum Dis 2021;80:930-42.

2 U.S. Food and Drug Administration (FDA). Fda adverse event reporting system, 2021. Available: https://www.fda.gov/drugs/questions-and-answers-fdas-adverse-eventreporting-system-faers/fda-adverse-event-reporting-system-faers-public-dashboard [Accessed 22 Feb 2021].

3 Roser M, Ortiz-Ospina E. Coronavirus pandemic (COVID-19). Our world in data. Available: https://ourworldindata.org/coronavirus [Accessed 13 Mar 2021].

4 Sormani MP, De Rossi N, Schiavetti I, et al. Disease-modifying therapies and coronavirus disease 2019 severity in multiple sclerosis. Ann Neurol 2021;89:780-9. 